are exaggerated, and he was not very confident of their potential usefulness except in relatively limited areas such as addressed display systems. In a stimulating paper, N. Boonthanom and M. White (Brighton Polytechnic) described the co-evaporation of metal/ polymer mixtures to form a structure of conducting metal islands in an insulating polymer matrix. In these films teh resistivity changes by seven orders of magnitude over a temperature range of only $200 \mathrm{~K}$.

The final session was concerned with the problems of fabricating magnetic bubble materials. It is a sign of the rate of progress in thin film physics that in such a recent development, the fundamental physics is already well established and the current problems are technological in nature.

\section{Nutrient supply and ecosystem growth}

\section{from Peter D. Moore,}

Plant Ecology Correspondent

THE term 'oceanicity' traditionally has conveyed to ecologists the impression of a climate with a low amplitude fluctuation in seasonal temperature and a high annual precipitation. There is now evidence, however, that other aspects of maritime environments-for example, nutrient cycling-may be of equal or greater ecological importance.

Nutrient elements in terrestrial ecosystems are cycled constantly between non-living and living components. There are gains and losses: gaseous elements are gained and lost through atmospheric movements; non-gaseous elements enter terrestrial ecosystems largely by means of the weathering of rock particles in the soil or as solutions or particulate fragments from the atmosphere, arriving as aerosol or dust. In some rather exceptional types of ecosystem other transport mechanisms may be important, such as inwash of detritus by rivers or sea, or the immigration of animals to roost, nest or defaecate. Nongaseous nutrient elements are lost from ecosystems largely as a result of soil leaching (see Bormann and Likens, Science, 155, 424; 1967).

In a stable, climax ecosystem nutrient gains are balanced by nutrient losses, whereas in seral ecosystems, still developing, gains exceed losses. The excess of gain over loss is normally associated with an increase in biomass. The final constraint which limits ecosystem development, however, is normally a climatic one rather than nutrient availability, although in some climax ecosystems (for example, ombrotrophic mires) nutrients may be limiting (Firbas, Veröff. geobot. Inst. Zurich, $25,177 ; 1952)$. It is possible, within the

\title{
More muonless neutrino events
}

from a Correspondent

LAST year the users of the European bubble chamber Gargamelle, at CERN Geneva, reported that they had observed neutrino interactions without outgoing muon tracks (Phys. Lett., 46B, 138; 1973; see also Nature 245, $119 ; 1973)$. The simplest explanation for these events is that the weak interaction has a 'neutral current' component. If the effect is genuine then the implications are profound. The existence of a neutral weak current makes it possible to construct a rigorous theory combining both the weak and the electromagnetic interactions. Such theories have been proposed by Weinberg (Phys. Rev., D5, 1412; 1972), and others.

When the Gargamelle result was announced there were unofficial reports that an American group had seen similar events in an experiment at the National Accelerator Laboratory (NAL) near Chicago. Now, after almost a year of careful checking, these data have been published (Benvenuti et al., Phys. Rev. Lett., 32, $800 ; 1974)$ by a combined team from Harvard, University of Pennsylvania, Wisconsin and NAL. The groups used scintillation-counter and spark-chamber techniques to detect the events, to measure the energy of the reaction products and to identify muon tracks. Their neutrinos were produced from primary proton beams of 300 and $400 \mathrm{GeV}$, much higher than the 30 GeV energy of the CERN proton beam.

The team saw 76 events which must have been caused by neutrino interactions, but did not have a muon track: 93 neutrino events were seen with an identification muon. A number of different techniques have been used to calculate how many muon events had been wrongly identified, in particular, how many muons missed the muon detector. All versions of this calculation fail to account for the whole of the observed signal of muonless events. About 36 genuine muonless events remain, giving a corected ratio of muonless events to muon events of $0.23+0.09$.

Since this ratio is almost the same as that seen by Gargamelle, even though the detection technique is totally different and the beam energies are ten times larger, there can now be no doubt that muonless neutrino events do occur. Whether they are caused by a neutral weak current is not yet completely certain, but other explanations are becoming increasingly implausible. general climatic restrictions, that availability of nutrients in an ecosystem could influence the rate at which succession takes place and equilibrium is attained.

In the light of this knowledge of nutrient cycling in ecosystems, it is rather surprising that nobody has yet attempted to measure the rates of successions in maritime regions where aerial nutrient input can be expected to be high and to compare these with areas of similar edaphic and climatic qualities far removed from the sea. Art, Bormann, Voigt and Woodwell (Science, 184,$60 ; 1974$ ) have now produced data from a maritime climax forest ecosystem which makes such a comparison even more imperative.

Fire Island, the research site, is a barrier island off Long Island, New York. It is fringed by sand dunes and salt marshes and contains a forest ecosystem in the lea of mature dunes. Art and his colleagues have attempted to determine the source of incoming nutrients to this forest and, by a process of elimination, they have come to the conclusion that aerosols and airborne particles constitute most of the nutrient input. They consider weathering an unimportant source of nutrients because the substrate is $98 \%$ quartz sand and the remainder (magnetite, garnet and tourmaline) is also unlikely to be a major source of ions. Animal inputs, mainly seabird guano, are only locally important and are of no significance within the study area. The soaking of seawater into the ecosystem from below does not occur because of the peculiar hydrology of the island; a high precipitation: evaporation ratio leads to a downward movement of freshwater to a depth of about $40 \mathrm{~m}$ below sea level in the centre of the island, thus excluding salt water. There remains the income from airborne sources.

Art et al. divide the airborne material into three types-a rain component (collected in rain gauges open only during rain), a dry fallout component (from gauges open all the time, less the rain component) and an impaction component (by measuring the difference between above canopy and below canopy composition of rainfall and determining the excess beneath canopy). Total annual figures of meteorological input obtained were (in $\mathrm{g} \mathrm{m}^{-2}$ ) : $0.73 \mathrm{~K}$; $14.15 \mathrm{Na}$; $0.98 \mathrm{Ca}$; and $1.91 \mathrm{Mg}$. These figures compare very closely with those obtained in other oceanic situations; for example, the Shetland Isles (see 